\title{
Effects of grain, fructose, and histidine feeding on endotoxin and oxidative stress measures in dairy heifers
}

\author{
H. M. Golder, ${ }^{*} \dagger^{1}$ I. J. Lean, ${ }^{*} \dagger$ A. R. Rabiee, ${ }^{*} \dagger$ R. King, $\ddagger$ and P. Celi ${ }^{\star} \S$ \\ *Dairy Science Group, Faculty of Veterinary Science, The University of Sydney, Camden, New South Wales, Australia 2570 \\ †SBScibus, Camden, New South Wales, Australia 2570 \\ ¥Dairy Australia, Southbank, Victoria, Australia 3006 \\ §Melbourne School of Land and Environment, The University of Melbourne, Parkville, Victoria, Australia 3052
}

\begin{abstract}
Ruminal endotoxin and plasma oxidative stress biomarker concentrations were studied in dairy heifers challenged with grain, fructose, and histidine in a partial factorial study. Holstein-Friesian heifers $[\mathrm{n}=$ 30; average body weight (BW) of $359.3 \pm 47.3 \mathrm{~kg}$ ] were randomly allocated to 5 treatment groups: (1) control (no grain); (2) grain [crushed triticale at $1.2 \%$ of $\mathrm{BW}$ dry matter intake (DMI)]; (3) grain (0.8\% of BW DMI) + fructose $(0.4 \%$ of BW DMI); (4) grain (1.2\% of BW DMI $)+$ histidine $(6 \mathrm{~g} /$ head $)$; and $(5)$ grain $(0.8 \%$ of BW DMI $)+$ fructose $(0.4 \%$ of BW DMI $)+$ histidine $(6 \mathrm{~g} /$ head $)$. Rumen samples were collected by stomach tube $5,65,115,165$, and 215 min after diet consumption and blood samples at 5 and 215 min after consumption. Rumen fluid was analyzed for endotoxin concentrations. Plasma was analyzed for concentrations of the following oxidative stress biomarkers: reactive oxygen metabolites (dROM), biological antioxidant potential (BAP), advanced oxidation protein products, and ceruloplasmin, and activity of glutathione peroxidase. Dietary treatment had no effect on concentrations of endotoxin or oxidative stress biomarkers. We observed no interactions of treatment by time. Ruminal concentrations of endotoxin decreased during the sampling period from $1.12 \times 10^{5} \pm 0.06$ to $0.92 \times 10^{5}$ endotoxin units $/ \mathrm{mL} \pm 0.05$ (5 and 215 min after diet consumption, respectively). Concentrations of $\mathrm{dROM}$ and the oxidative stress index $(\mathrm{dROM} / \mathrm{BAP} \times 100)$ increased over the sampling period, from 108.7 to 123.5 Carratelli units (Carr U), and from 4.1 to 4.8 , respectively. Ceruloplasmin concentrations markedly declined 5 min after the consumption of diets, from 190 to $90 \mathrm{mg} / \mathrm{L}$ over the 215-min sampling period. Overall, a single feeding challenge for dairy cattle with grain, fructose, and histidine, and combinations thereof, may not be sufficient
\end{abstract}

Received June 10, 2013.

Accepted August 21, 2013.

${ }^{1}$ Corresponding author: heleng@sbscibus.com.au to induce marked changes in endotoxin or oxidative stress biomarker concentrations.

Key words: endotoxin, fructose, histidine, oxidative stress

\section{INTRODUCTION}

Cattle are at an increased risk of acidosis during the transition period because they are often exposed to abrupt increases in rapidly fermentable carbohydrates (Penner et al., 2007) following reduced DMI before parturition (Hayirli et al., 2003). Similarly, abrupt exposures can occur in beef cattle fed feedlot diets. Without a gradual introduction and sufficient effective fiber, carbohydrates cause organic acids to accumulate in the rumen and exceed its buffering capacity, resulting in ruminal acidosis (Nagaraja and Titgemeyer, 2007; RAGFAR, 2007; Plaizier et al., 2008). Ruminal acidosis is a complex nutritional disorder ranging in severity from the peracute form, resulting in death, to relatively mild forms where symptoms can be subclinical. Measures of ruminal $\mathrm{pH}$ are often used for diagnosis, but inconsistencies in cut-off thresholds that define acidosis severity have created confusion regarding the accurate diagnosis of acidosis (Kleen et al., 2003; Nagaraja and Titgemeyer, 2007; Plaizier et al., 2008). Bramley et al. (2008) showed that ruminal valerate and propionate were the most effective ruminal fermentation parameters for diagnosing acidosis, and ruminal $\mathrm{pH}$ and lactate were the least effective. The model of acidosis developed by Bramley et al. (2008) is the only method that defines acidosis on the basis of changes in ruminal measures and relates these to diet, health, and production. We hypothesize that acidosis occurs along a continuum of ruminal conditions ranging from clinical acidosis to normal and that testing responses of cattle to feeding challenges in this range will increase our understanding of the pathogenesis and means to control acidosis.

Despite extensive research and many detailed reviews (Owens et al., 1998; Krause and Oetzel, 2006; RAGFAR, 2007; Enemark, 2008; Plaizier et al., 2008), the patho- 
genesis of acidosis is still not completely understood, particularly in regard to the proposed involvement of specific molecules such as endotoxins (Khafipour et al., 2009a) and histamine (Ahrens, 1967), and involvement of specific microbial species. Most research has focused on changes resulting from several days or weeks of repeated exposure to rapidly fermentable carbohydrates. Changes resulting from single exposure to readily fermentable carbohydrate in the first hours after feeding in cattle not adapted to these diets have received less attention but could provide important insights into acidosis development, especially around parturition or introduction to feedlots.

In our previous study, we were able to show that dairy cattle fed a single grain challenge ( 0.8 or $1.2 \%$ of BW DMI) after $14 \mathrm{~h}$ off feed had increased concentrations of ammonia, total VFA, acetate, butyrate, propionate, and valerate, and decreased $\mathrm{pH}$ compared with cattle fed no grain (Golder et al., 2012). We also observed that dairy cattle fed $0.8 \%$ of BW DM grain and $0.4 \%$ of BW DM fructose in a single challenge after feed withholding had markedly increased ruminal lactate, total VFA, butyrate concentrations and decreased ruminal valerate concentration and $\mathrm{pH}$ (Golder et al., 2012). We conclude that these carbohydrate challenges, which reflect those occurring in dairy cattle during the transition period and that induced significant changes in rumen fermentation profile, are worthy of further investigation.

Endotoxins are lipopolysaccharides released from the cell walls of gram-negative bacteria during bacterial multiplication and lysis (Rietschel et al., 1994). High concentrations of endotoxin in the rumen have been implicated in contributing to the nonspecific, acute phase response during SARA induced by feeding high levels of concentrate over several days (Gozho et al., 2007; Khafipour et al., 2009a). A meta-analysis has shown that increased dietary concentrate content and reduced dietary NDF content are associated with an increase in ruminal endotoxin, plasma haptoglobin, and serum amyloid A levels (Zebeli et al., 2012). Responses became linear when cattle were fed $>44.1 \%$ concentrate or $<39.2 \%$ NDF (Zebeli et al., 2012). Cattle in these studies were exposed to high fermentation carbohydrate diets over a series of days. High concentrations of endotoxin may be responsible for some of the observed clinical signs of acidosis, including inflammation, laminitis, and liver abscesses (Plaizier et al., 2012). Similar depressions in ruminal $\mathrm{pH}$ for cattle challenge-fed with alfalfa pellet and ground alfalfa to those observed in high concentrate challenges suggest that ruminal $\mathrm{pH}$ depressions and increased endotoxin alone do not cause an acute phase response (Plaizier et al., 2012). It is unclear whether endotoxin concentrations change dur- ing the first few hours after single exposures to rapidly fermentable carbohydrates. Increases by $6 \mathrm{~h}$ and peaks at $12 \mathrm{~h}$ have been reported in dairy cattle fed grain challenges over several days (Gozho et al., 2006; Khafipour et al., 2009a). Translocation of free endotoxin into the bloodstream can result in the production of proinflammatory cytokines, reactive oxygen, and bioactive lipids (Rietschel et al., 1994). Endotoxin can cause inflammation and increased oxidative reactions. Oxidative stress occurs when the presence of pro-oxidative metabolites exceeds the capacity of antioxidants to neutralize these (Miller et al., 1993). It is a relatively new field of research in ruminants but has been implicated in numerous disease processes in cattle (Celi, 2011a). Prolonged concentrate feeding in dairy cattle increased plasma glutathione peroxidase activity and lipid peroxidation, and decreased $\alpha$-tocopherol and ferric reducing ability of plasma (Wullepit et al., 2009). An increase in oxidative stress was also reported by Gabai et al. (2004) when high levels of starch were fed to dairy cows at 80 DIM. Further research is needed to explore links between abruptly feeding rapidly fermentable carbohydrates, endotoxin, and oxidative stress in cattle and to determine thresholds for these changes in metabolism.

The objective of this study was to investigate the effects of grain, fructose, and histidine, and their combinations, fed to dairy heifers unadapted to these in a single challenge on ruminal endotoxin and plasma oxidative stress biomarker concentrations. We hypothesized that grain would increase endotoxin concentrations and induce oxidative stress responses as a result of increased VFA and decreased ruminal $\mathrm{pH}$ compared with heifers fed no grain. Fructose was hypothesized to induce greater concentrations of endotoxin and more pronounced oxidative stress responses than grain because of more rapid fermentation rates and observed higher ruminal total VFA, butyrate, and lactic acid concentrations than induced by grain alone. We hypothesized that histidine would have no effect on endotoxin or oxidative stress responses because no main effects on rumen fermentation profile were observed from histidine addition (Golder et al., 2012).

\section{MATERIALS AND METHODS}

\section{Animals and Experimental Protocol}

The experiment was conducted on 30 nonpregnant Holstein-Friesian heifers $<18$ mo of age with an average $\mathrm{BW}$ of $359.3 \pm 47.3 \mathrm{~kg}$ at Camden (NSW, Australia). The animals were from a commercial dairy herd, and all experimental procedures were approved by the Bovine Research Australasia Animal Ethics Committee. The 
Table 1. Chemical composition of alfalfa hay and ryegrass silage fed during the adaptation period, and triticale cultivar 'Berkshire' fed during the adaptation and challenge periods ${ }^{1}$

\begin{tabular}{|c|c|c|c|}
\hline $\begin{array}{l}\text { Item }^{2} \\
(\% \text { of DM) }\end{array}$ & $\begin{array}{c}\text { Alfalfa } \\
\text { hay }\end{array}$ & $\begin{array}{l}\text { Ryegrass } \\
\text { silage }\end{array}$ & Triticale \\
\hline $\mathrm{DM}$ & 87.7 & 76.2 & 88.8 \\
\hline $\mathrm{NDF}$ & 45.9 & 52.3 & 22.1 \\
\hline $\mathrm{CP}$ & 20.7 & 17.7 & 16.7 \\
\hline Soluble protein ( $\%$ of CP) & 43 & 40.5 & 26.5 \\
\hline Crude fat & 2.5 & 2.6 & 1.5 \\
\hline Ash & 9.0 & 10.4 & 2.4 \\
\hline Lignin & 6.8 & 6.5 & 2.3 \\
\hline $\mathrm{ADF}$ & 33.6 & 35.6 & 5.3 \\
\hline ADICP & 1.2 & 1.5 & 0.3 \\
\hline NDICP & 3.5 & 5.6 & 2.9 \\
\hline $\mathrm{NFC}$ & 25.5 & 22.8 & 60.0 \\
\hline Available protein & 19.5 & 16.2 & 16.5 \\
\hline Degradable protein (\% CP) & 69 & 64 & 70 \\
\hline Starch & 2.5 & 1.7 & 51.7 \\
\hline Water-soluble carbohydrates & 7.2 & 7.5 & - \\
\hline ESC (simple sugars) & 4.9 & 7.3 & 3.8 \\
\hline DCAD $(\mathrm{mEq} / 100 \mathrm{~g})$ & 20 & 5 & 1 \\
\hline \multicolumn{4}{|l|}{ Minerals $(\mathrm{mg} / \mathrm{kg})$} \\
\hline Chloride & 9,388 & 16,367 & 1,358 \\
\hline Calcium & 10,002 & 9,828 & 357 \\
\hline Cobalt & $<0.5$ & 1.60 & $<0.5$ \\
\hline Copper & 7.7 & 9.6 & 6.1 \\
\hline Iron & 228 & 1,393 & 57.6 \\
\hline Phosphorus & 3,400 & 2,700 & 3,000 \\
\hline Potassium & 24,170 & 19,730 & 6,625 \\
\hline Magnesium & 2,906 & 3,608 & 1,300 \\
\hline Manganese & 56.2 & 139 & 57.3 \\
\hline Molybdenum & 0.8 & 0.7 & 0.6 \\
\hline Sodium & 1,440 & 4,510 & 100 \\
\hline Sulfur & 3,000 & 3,400 & 1,900 \\
\hline Zinc & 29 & 27 & 42 \\
\hline
\end{tabular}

${ }^{1}$ Values are means obtained from near-infrared spectroscopy and wet chemistry.

${ }^{2} \mathrm{ADICP}=$ acid detergent insoluble $\mathrm{CP} ; \mathrm{NDICP}=$ neutral detergent insoluble $\mathrm{CP} ; \mathrm{NFC}=100-[(\mathrm{NDF}-$ NDICP $)+\mathrm{CP}+$ crude fat + ash]; ESC (simple sugars) = ethanol-soluble carbohydrate.

experimental procedures of this study have previously been detailed by Golder et al. (2012).

Briefly, heifers were housed on a dry lot and were fed $1 \mathrm{~kg}$ (as-fed basis) of grain daily, with ad libitum access to ryegrass silage and alfalfa hay twice daily in individual head stanchions in a feedpad for a 10-d adaptation period before the challenge day. Target feed intake was $2 \mathrm{~kg} / \mathrm{d}$ of alfalfa hay, $7.2 \mathrm{~kg} / \mathrm{d}$ of ryegrass silage, and $1 \mathrm{~kg} / \mathrm{d}$ of triticale (as-fed basis). The estimated chemical composition of the diet (CPM Dairy V3.10; Cornell-Penn-Miner, Cornell University, Ithaca, $\mathrm{NY}$ ) during the adaptation period was $\mathrm{NDF}=42.3 \%$ of DM, lignin $=5.6 \%$ of DM, NFC $=30.2 \%$ of DM, silage acids $=6.5 \%$ of DM, sugar $=7.0 \%$ of DM, starch $=7.7 \%$ of DM, and soluble fiber $=8.9 \%$ of DM. The chemical composition of the alfalfa hay, ryegrass silage, and triticale cultivar 'Berkshire' were analyzed by nearinfrared spectroscopy and wet chemistry by George Weston Technologies (Sydney, NSW, Australia) and Dairy One Inc. Forage Testing Laboratory (Ithaca, NY; Table 1). Wet chemistry techniques were described by Golder et al. (2012).
The heifers were randomly allocated to the following 5 treatment groups $(\mathrm{n}=6$ heifers/group) in a partial factorial arrangement: (1) control (no grain); (2) grain (1.2\% of BW DMI of crushed triticale cultivar 'Berkshire'); (3) grain $(0.8 \%$ of BW DMI $)+$ fructose $(0.4 \%$ of BW DMI); (4) grain (1.2\% of BW DMI) + histidine $(6 \mathrm{~g} / \mathrm{head})$; and (5) grain $(0.8 \%$ of BW DMI $)+$ fructose $(0.4 \%$ of BW DMI $)+$ histidine $(6 \mathrm{~g} /$ head $)$. The statistical power of the study was based on previous experiments conducted by the group that demonstrated significant differences in VFA using a smaller number of animals per group than used in this study. The fructose (Melbourne Food Depot, East Brunswick, VIC, Australia) was a $99.5 \%$ pure crystalline powder and was mixed through the grain ration. The mean weight of fructose administered at a rate of $0.4 \%$ of BW $(33 \%$ of DM) was $1.44 \mathrm{~kg}$. This is equivalent to the amount of water-soluble carbohydrate a heifer may consume over an entire day. The histidine (Merck KGaA, Darmstadt, Germany) was an L-histidine powder dissolved in 50 $\mathrm{mL}$ of tap water and was administered via a stomach tube immediately after consumption of $200 \mathrm{~g}$ of alfalfa 
hay. The dose rate of $6 \mathrm{~g}$ of histidine per head corresponds to approximately $160 \%$ of the average daily histidine requirement of $400-\mathrm{kg}$ heifers as calculated in CPM Dairy V3.10.

The challenges were conducted over 4 consecutive days, with 7 or 8 heifers randomly allocated to 1 of the $4 \mathrm{~d}$, with at least 1 heifer from each group sampled on each day. Feed was withheld for $14 \mathrm{~h}$ before challenge. On the challenge day, each heifer was offered and ate $200 \mathrm{~g}$ of alfalfa hay to reduce saliva contamination. Immediately after the hay was consumed, their allocated treatment diets were offered, except for the control group, which received no further ration. Heifers in the 2 nonfructose groups consumed $99.5 \%$ of the allocated grain, in a mean time of $28 \mathrm{~min} \pm 5 \mathrm{~min}$. Fructose-fed heifers consumed $75.7 \% \pm 5.3$ of allocated grain and $74 \% \pm 8.5$ of fructose in a mean time of $65 \mathrm{~min} \pm$ 4.4 (Golder et al., 2012). Heifers exhibited no visible signs of clinical acidosis or lameness during or after the experimental periods.

\section{Sampling}

Rumen fluid samples were collected 5, 65, 115, 165, and 215 min after dietary treatment consumption via a stomach tube and custom-designed stomach pump, centrifuged at $1,512 \times g$ for $15 \mathrm{~min}$ at $5^{\circ} \mathrm{C}$, and stored at $-20^{\circ} \mathrm{C}$ for endotoxin analysis. Rumen fluid was scored for saliva contamination as described by Bramley et al. (2008) using a 1- to 3-point scoring system (3 being highest level of contamination). No rumen samples retained for analysis had a saliva score $>1$. Blood samples were taken via jugular venipuncture immediately after 5 - and 215-min rumen fluid collections in heparinized blood collection tubes (BD Vacutainer, Plymouth, UK). Blood samples were centrifuged at $1,512 \times g$ for $15 \mathrm{~min}$ at $5^{\circ} \mathrm{C}$, and plasma was stored at $-20^{\circ} \mathrm{C}$ for the laboratory analysis of derivatives of reactive oxygen metabolites (dROM), biological antioxidant potential (BAP), advanced oxidation protein products (AOPP), glutathione peroxidase (GSH-Px), and ceruloplasmin.

\section{Assays}

Endotoxin concentrations were determined in the 5-, 115-, and 215-min rumen fluid samples by a chromogenic endpoint Limulus amoebocyte lysate (LAL) assay with a sensitivity of 0.1 to 1 endotoxin units $(\mathbf{E U}) / \mathrm{mL}$ (QCL-1000; Lonza Australia Pty. Ltd., Mount Waverley VIC, Australia). Certified pyrogenfree (endotoxin content $<0.001 \mathrm{EU} / \mathrm{mL}$ ) microplates, pipette tips, and glassware were used throughout the experiment. Rumen fluid samples were diluted $62,500-$ fold with pyrogen-free water (endotoxin content $<0.005$ $\mathrm{EU} / \mathrm{mL}$ ) and incubated in a $70^{\circ} \mathrm{C}$ water bath for $20 \mathrm{~min}$ to remove most of the other LAL-gelating compounds (Baek et al., 1985). Microplates were pre-equilibrated to $37^{\circ} \mathrm{C}$ on a heating block (DBH 20D; Ratek, Boronia, VIC, Australia) and remained on the heating block for the duration of the assay. A total of $50 \mu \mathrm{L}$ of sample or standard was dispensed into the appropriate microplate well. Limulus amoebocyte lysate $(50 \mu \mathrm{L})$ was then added to each well and incubated for 12 min. Thereafter, $100 \mu \mathrm{L}$ of chromogenic substrate was added and the microplate was incubated for a further $15 \mathrm{~min}$ before the reaction was stopped by adding $25 \%$ ( $\mathrm{vol} / \mathrm{vol}$ ) acetic acid (Sigma-Aldrich, Sydney, NSW, Australia). The absorbance was then read at $405 \mathrm{~nm}$ (POLARstar Optima; BMG Labtech, Melbourne, VIC, Australia). Endotoxin concentrations were calculated from the standard curve and multiplied by the dilution factor.

The amount of free oxygen radicals in plasma samples were determined by measuring the concentrations of dROM, using a colorimetric assay according to kit instructions (d-ROMS Test, Diacron International, Grosseto, Italy; Cesarone et al., 1999). This test works on the principle that the plasma is diluted in an acidic buffer solution, allowing iron ions to be released from the plasma proteins to catalyze the breakdown of hydroperoxide to alkoxyl and peroxyl radicals. A chromogen ( $N, N$-dietylparaphenylendiamine) is then added and changes color as it is oxidized by hydroperoxyl and alkoxyl radicals. The concentration of the colored complex is directly related to the level of hydroperoxide in the sample and can be photometrically quantified at 505 nm (Alberti et al., 2000). The results are expressed in Carratelli units (Carr U), where 1 Carr U corresponds to $0.08 \mathrm{mg} / 100 \mathrm{~mL}$ of hydrogen peroxide.

The concentrations of antioxidants were measured using the BAP test according to kit instructions (Diacron International). This test provides a combined measurement of several antioxidants including uric acid, ascorbic acid, proteins, $\alpha$-tocopherol, and bilirubin by measuring the BAP of the plasma sample to reduce ferric $\left(\mathrm{Fe}^{3+}\right)$ to ferrous $\left(\mathrm{Fe}^{2+}\right)$ iron (Benzie and Strain, 1996). The results of BAP are expressed in micromoles per liter of reduced iron. The extent of oxidative stress was expressed as an oxidative stress index (OSI), which was estimated using the ratio dROM:BAP $\times 100$, as the combination of $\mathrm{dROM}$ and $\mathrm{BAP}$ results provides a more accurate representation of oxidative stress status (Celi, 2011b).

Advanced oxidation protein products were measured according to the methods of Witko-Sarsat et al. (1998). In summary, $200 \mu \mathrm{L}$ of plasma was diluted $1 / 5$ in PBS $(5 \mathrm{mM})$ and placed into a 96-well, and then $20 \mu \mathrm{L}$ of glacial acetic acid was added. A chloramine-T solution 
(Sigma-Aldrich) was used to produce a standard curve ranging from 0 to $200 \mu \mathrm{mol} / \mathrm{L}$. In standard wells, 10 $\mu \mathrm{L}$ of $1.16 M$ potassium iodide (ReagentPlus, SigmaAldrich) was added to $200 \mu \mathrm{L}$ of chloramine-T solution followed by $20 \mu \mathrm{L}$ of acetic acid. Within $5 \mathrm{~min}$, the absorbance was read at $340 \mathrm{~nm}$ (POLARstar Optima, BMG Labtech). Concentrations of AOPP were expressed as micromoles per liter of chloramine- $\mathrm{T}$ equivalents.

The concentrations of plasma GSH-Px were measured based on a spectrometric method according to kit instructions (kit no. 703102; Cayman, Ann Arbor, MI). The absorbance of the samples was recorded for a 4 -min period at $60-\mathrm{s}$ intervals at $340 \mathrm{~nm}$ (POLARstar Optima, BMG Labtech).

Plasma ceruloplasmin concentrations were determined according to the methods described by Sunderman and Nomoto (1970) except that absorbance was read at $510 \mathrm{~nm}$ (POLARstar Optima, BMG Labtech). Briefly, $2 \mathrm{~mL}$ of acetate buffer solution and $100 \mu \mathrm{L}$ of plasma were added to 2 sets of glass tubes for each sample, a set for the reaction $(\mathbf{R})$ and a set for the blank (B). All tubes were brought to thermal equilibrium in a $37^{\circ} \mathrm{C}$ water bath. To all tubes, $1 \mathrm{~mL}$ of $37^{\circ} \mathrm{C}$ p-phenylendiamine solution (Sigma-Aldrich) was added and mixed, and all tubes were incubated in a $37^{\circ} \mathrm{C}$ water bath for $5 \mathrm{~min}$ unstoppered. To the $\mathrm{B}$ tubes only, $50 \mu \mathrm{L}$ of sodium azide solution (Sigma-Aldrich) was added and mixed. After a 30-min incubation of all tubes, $50 \mu \mathrm{L}$ of sodium azide solution (Sigma-Aldrich) was added to the $\mathrm{R}$ tubes. A total of $300 \mu \mathrm{L}$ of solution from each tube was pipetted on a micro-plate and absorbance was read at $510 \mathrm{~nm}$ (FLUROstar Optima, BMG Labtech). The ceruloplasmin concentration was calculated as follows:

$$
\text { Ceruloplasmin }(\mathrm{g} / \mathrm{L})=0.752\left(\mathrm{~A}_{\mathrm{R}}-\mathrm{A}_{\mathrm{B}}\right) \text {, }
$$

where $A_{R}$ is the absorbance of sample $R$, and $A_{B}$ is the absorbance of sample B.

\section{Statistical Analysis}

A general linear model with repeated measures was used to estimate the effect of time, treatment group, and time $\times$ treatment interaction (PASW Statistics 18, SPSS Inc., Chicago, IL). The blocking effect of day was not significant and removed from the final model. The co-variance structure was independent and a Tukey test was performed for means separation over time. The model was as follows:

$$
\mathrm{Y}_{\mathrm{ijk}}=\mu+\beta_{\mathrm{i}}+\gamma_{\mathrm{j}}+(\beta \gamma)_{\mathrm{ij}}+\mathrm{R} \varepsilon_{\mathrm{ijk}},
$$

where $\mathrm{Y}_{\mathrm{ijk}}=$ response at treatment $\mathrm{i}(\mathrm{i}=1$ to 5$)$ at time $\mathrm{j}(\mathrm{j}=1$ or 2$)$ by heifer $\mathrm{k}(\mathrm{k}=1$ to 30$) ; \mu=$ overall mean; $\beta_{\mathrm{i}}=$ effect of treatment; $\gamma_{\mathrm{j}}=$ effect of time $\mathrm{j} ;(\beta \gamma)_{\mathrm{ij}}=$ effect of treatment by time interaction; and $R \varepsilon_{\mathrm{ijk}}=$ random residual error adjusted for repeated measurements within heifer $\mathrm{k}$ at time $\mathrm{j}$

To estimate the main effects of grain, fructose, and histidine, and their interactions by time, the 5 treatment groups were merged into a factorial arrangement and analyzed using generalized estimating equations (GEE) with repeated measures using the PROC MIXED methods in SAS (version 9.2, SAS Institute Inc., Cary, NC; Golder et al., 2012). A Pearson correlation (PASW Statistics 18, SPSS Inc.) was performed to determine the correlations between all measures of ruminal $\mathrm{pH}$, rumen fermentation products, and rumen endotoxin, and plasma oxidative stress biomarkers at 5 and 215 min after dietary treatment consumption.

\section{RESULTS}

No time $\times$ treatment interaction or effect of treatment was observed for endotoxin concentration or oxidative stress biomarkers (Table 2); however, we observed a trend toward a decrease in AOPP concentration over time in the control group $(P=0.08$; Table 2 ; Figure 2D). Concentrations of ruminal endotoxin decreased over the experimental period from $1.12 \times 10^{5}$ $\pm 0.06 \mathrm{EU} / \mathrm{mL}$ at $5 \mathrm{~min}$ after treatment consumption to $0.92 \times 10^{5} \mathrm{EU} / \mathrm{mL} \pm 0.05 \mathrm{EU} / \mathrm{mL}$ at $215 \mathrm{~min}$ after consumption $(P=0.02$; Figure 1$)$. Concentrations of dROM increased over time $(P=0.002)$ from $108.7 \pm$ 4.1 to $123.5 \pm 3.3$ Carr $U$ at 5 and 215 min, respectively after treatment consumption (Figure 2A). The OSI also increased over the experimental period, from $4.1 \pm 0.02$ at $5 \mathrm{~min}(P=0.009)$ to $4.8 \pm 0.03$ at $215 \mathrm{~min}$ after consumption (Figure 2C). Ceruloplasmin concentrations decreased by half $(P<0.001)$ over time from 190 \pm 70 at 5 min after treatment consumption to $90 \pm 10$ $\mathrm{mg} / \mathrm{L}$ at $215 \mathrm{~min}$ after treatment consumption (Figure $2 \mathrm{~F})$. No time effect was observed for BAP, AOPP, or GSH-Px concentrations (Table 2; Figure 2B, D, E).

We observed no effects of grain, fructose, and histidine, or their interactions by time for ruminal endotoxin concentrations or any plasma oxidative stress biomarkers in the generalized estimating equations with repeated-measures merged factorial analysis (data not shown).

Ruminal histamine and propionate were negatively correlated with OSI at $215 \mathrm{~min}(\mathrm{r}=-0.42 ; P=0.02$ and $\mathrm{r}=-0.39 ; P=0.09$, respectively). Acetate was negatively correlated with the OSI at $215 \mathrm{~min}(\mathrm{r}=$ $-0.41 ; P=0.02)$. No other correlations were found between the ruminal parameters analyzed by Golder et 
Table 2. Least squares means $( \pm \mathrm{SEM})$ of treatment groups and main effects ( $P$-values) of treatment groups, time, and their interaction for ruminal endotoxin and plasma oxidative stress biomarkers $(\mathrm{n}=6$ heifers/group)

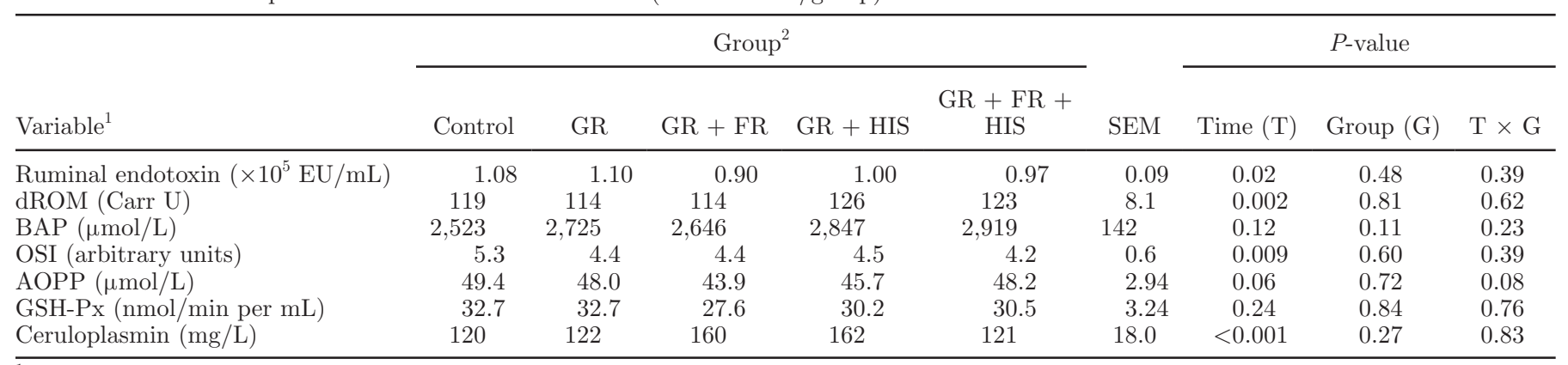

${ }^{1} \mathrm{EU}=$ endotoxin units; $\mathrm{dROM}=$ reactive oxygen metabolites (Carr $\mathrm{U}=$ Carratelli units; 1 Carr $\mathrm{U}=0.08 \mathrm{mg} / 100 \mathrm{~mL}$ of hydrogen peroxide); $\mathrm{BAP}=$ biological antioxidant potential; OSI $=$ oxidative stress index; AOPP $=$ advanced oxidative protein products; GSH-Px $=$ glutathione peroxidase.

${ }^{2}$ Control $=$ no grain; GR $=$ crushed triticale at $1.2 \%$ of BW DMI; GR + FR = grain $(0.8 \%$ of BW DMI $)+$ fructose $(0.4 \%$ of BW DMI $)$; GR + HIS $=$ grain $(1.2 \%$ of BW DMI $)+$ histidine $(6 \mathrm{~g} /$ head $) ; \mathrm{GR}+\mathrm{FR}+\mathrm{HIS}=$ grain $(0.8 \%$ of BW DMI $)+$ fructose $(0.4 \%$ of $\mathrm{BW}$ DMI $)+$ histidine $(6 \mathrm{~g} / \mathrm{head})$.

al. (2012) and endotoxin and oxidative stress biomarker concentrations at either 5 or 215 min.

\section{DISCUSSION}

Although no clinical signs of acidosis were observed, changes in the ruminal fermentation profile, particularly valerate, propionate, and lactic acid concentrations, suggested that these heifers were exposed to a significant challenge diet (Golder et al., 2012). Lactic acid concentrations were 22- and 21-fold higher in the fructose groups than in the controls (Golder et al., 2012), indicating the strength of the challenge and potential for endotoxin generation (Zebeli et al., 2011). The ruminal fermentation changes observed by Golder et al. (2012) identified group effects of diet on fermentation. From the results of this study, we rejected the hypothesis that a single grain and fructose challenge in dairy heifers would increase ruminal endotoxin concentrations and induce plasma oxidative stress responses. Histidine had no effect on either endotoxin or oxidative stress biomarker concentrations, as hypothesized. The previous findings (Golder et al., 2012) demonstrate that the lack of significant endotoxin and oxidative stress responses were not primarily attributable to type II error but reflect the efficacy of mechanisms that control ruminal metabolism during periods of significant dietary challenge, such as that encountered around parturition or on feedlot entry diets.

The absence of a group effect for both endotoxin and oxidative stress measures provides a useful contribution to the limited field of research into links between nutrition, inflammation, and oxidative stress. It highlights the difference between rumen environments of carbohydrate-challenged cattle in this study and acute carbohydrate challenge models used in other cattle studies (Andersen and Jarlov, 1990; Andersen et al., 1994). Similarly, it identifies changes occurring during disease progression from initial carbohydrate insults in this study and repeated carbohydrate exposures (Gozho et al., 2007; Emmanuel et al., 2008; Khafipour et al., 2009a).

The endotoxin concentrations in our study are consistent with the values reported in cattle fed concentrate or alfalfa pellet (Khafipour et al., 2009a,b) and cattle fed concentrate (Gozho et al., 2007). These concentrations are higher than those reported by Plaizier et al. (2012) and Khafipour et al. (2009a) for control and challenge group concentrations. The difference in the range of endotoxin values may be accounted for by variation between animals, diets, and assays (Khafipour et al., 2009a).

Acidosis develops from a progression of changes in bacterial population, fermentation products, and physiological functions, suggesting that a substrate $\times$ time interaction for ruminal endotoxin could occur; this effect was not observed. We hypothesized that grain would increase endotoxin concentrations in response to the increased availability of carbohydrate substrates and changes in bacterial populations reflected in decreased ruminal $\mathrm{pH}$, and markedly increased VFA concentrations (Golder et al., 2012). Endotoxin is continuously present in the rumen as the result of release from gram-negative bacteria during multiplication and lysis (Rietschel et al., 1994). The bacterial ecological balance, effects of ruminal $\mathrm{pH}$ on metabolism, changes in the cell membrane of bacteria, and other physiological functions of the rumen should modulate the release and accumulation of ruminal endotoxin (Russell and Rychlik, 2001; Ametaj et al., 2010). Substitution of fructose for grain increased mean D- and L-lactate concentrations by 22- and 21-fold, respectively, over other 
groups, increased total VFA and butyrate concentrations, and decreased valerate concentrations and ruminal pH (Golder et al., 2012). It was therefore hypothesized that fructose would increase endotoxin release compared with that in grain-fed animals in response to increased bacterial multiplication and lysis, reflecting the faster fermentation rate of sugars than starches (Firkins, 2011). Despite the substantial differences in fermentation, feeding a challenge diet of grain and fructose had no effect on ruminal endotoxin concentrations over the first $3.6 \mathrm{~h}$ after feeding. Others have reported increased ruminal endotoxin concentrations in grain-based challenge studies in dairy cows (Motoi et al., 1993; Gozho et al., 2007; Emmanuel et al., 2008; Khafipour et al., 2009a). A meta-analysis has shown that increased dietary concentrate content and reduced dietary NDF content are associated with an increase in ruminal endotoxin, plasma haptoglobin, and serum amyloid A levels (Zebeli et al., 2012). Responses became linear when cattle were fed $>44.1 \%$ concentrate or $<39.2 \%$ NDF (Zebeli et al., 2012). In these studies, the challenge diets were fed over several days, in contrast to the single challenge in this study. This observation may account for the difference in outcomes observed, as bacterial populations could undergo greater population shifts, possibly resulting in greater bacterial lysis.

It is necessary to establish the thresholds at which endotoxin release is increased after abrupt increases in carbohydrate feeding. Abrupt acute concentrate challenges in dairy cattle have not resulted in consistent endotoxin responses, with no difference reported by Andersen and Jarlov (1990), an increase reported by Nagaraja et al. (1978), and increases in cattle fed $4 \mathrm{~kg}$ of concentrate after having been fed hay in the previous month, reported by Andersen et al. (1994). Differences in findings among these studies may also reflect differences in age, physiological state of the dairy cattle, challenge diet composition, challenge management, and difference in assay methods. The dairy cattle in this study were unmated heifers, and metabolic changes may not be as pronounced in these cattle as in lactating cows under greater metabolic stress (Li et al., 2012). No other studies have examined the effects of sugar or histidine on endotoxin concentrations.

Endotoxin concentrations decreased over the 215-min period of the study, in contrast to the observed increase in VFA production (Golder et al., 2012), whereas increases in ruminal endotoxin concentrations were observed by $6 \mathrm{~h}$ after carbohydrate-induced challenge in dairy cattle and peaked $12 \mathrm{~h}$ after (Gozho et al., 2006; Khafipour et al., 2009a). Endotoxin concentrations increased over consecutive days during carbohydrate feeding (Gozho et al., 2005, 2007); however, endotoxin concentrations decreased by $25 \%$ over $4 \mathrm{~d}$ after acute carbohydrate challenge in cattle (Andersen and Jarlov, 1990). The involvement of ruminal endotoxin in the pathogenesis of grain-related disorders remains unclear, given the varied responses to abrupt challenges with carbohydrate including that in this study and requires further investigation.

We hypothesized that the proinflammatory molecule histamine, which increased with grain feeding in this study ( $P=0.054$; Golder et al., 2012), would be positively correlated with endotoxin and oxidative stress measures; however, this was not the case.

The measurement of oxidative stress parameters in unmated dairy heifers is unique and contributes to the currently small amount of data on oxidative stress in dairy cattle. At present, the normal ranges for oxidative stress measures in dairy cattle in different physiological states are not defined.

Biomarkers of oxidative stress were hypothesized to increase in grain and fructose fed heifers, reflecting the observed decreases in ruminal $\mathrm{pH}$, increases in total VFA, and marked increases in lactic acid in fructose-fed heifers. Changes were proposed to be more pronounced in the fructose-fed heifers compared with the heifers fed grain only or control heifers. However, oxidative stress biomarkers were not affected by treatments, indicat-

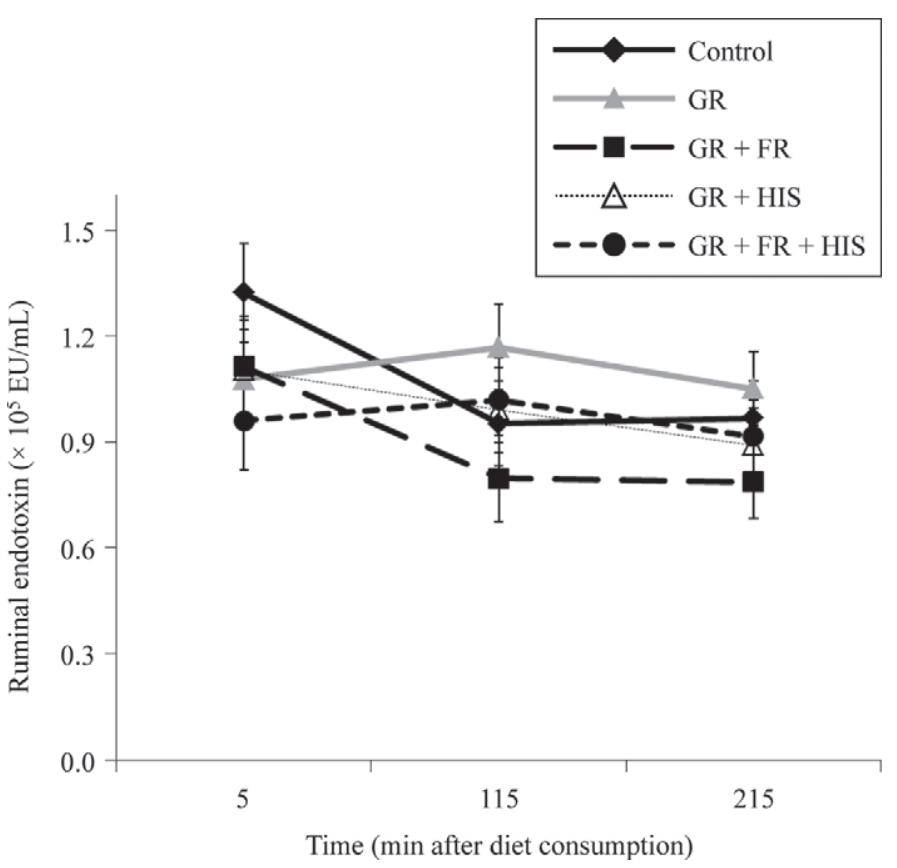

Figure 1. Ruminal concentrations of endotoxin (mean \pm SEM) 5,115 , and 215 min after feed consumption in dairy heifers fed 5 different challenge diets ( $\mathrm{n}=6$ heifers/group): control (no grain); GR $=$ (crushed triticale, $1.2 \%$ of BW DMI ); $\mathrm{GR}+\mathrm{FR}=$ grain $(0.8 \%$ of $\mathrm{BW}$ DMI $)+$ fructose $(0.4 \%$ of BW DMI $) ; \mathrm{GR}+\mathrm{HIS}=$ grain $(1.2 \%$ of BW DMI $)+$ histidine $(6 \mathrm{~g} /$ head $) ; \mathrm{GR}+\mathrm{FR}+\mathrm{HIS}=$ grain $(0.8 \%$ of BW DMI $)+$ fructose $(0.4 \%$ of BW DMI $)+$ histidine $(6 \mathrm{~g} /$ head $)$. $\mathrm{EU}=$ endotoxin units 

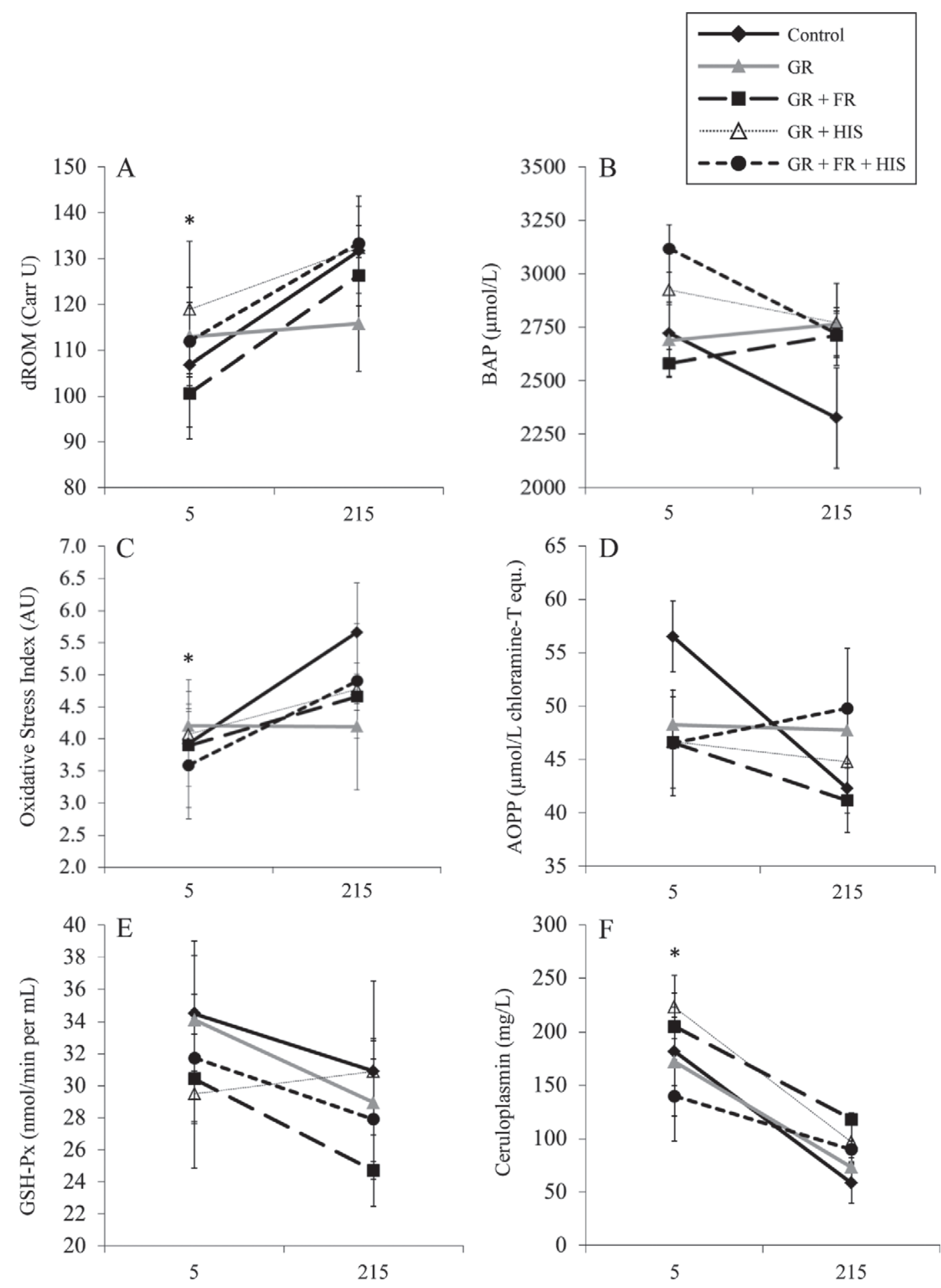

Time (min after diet consumption)

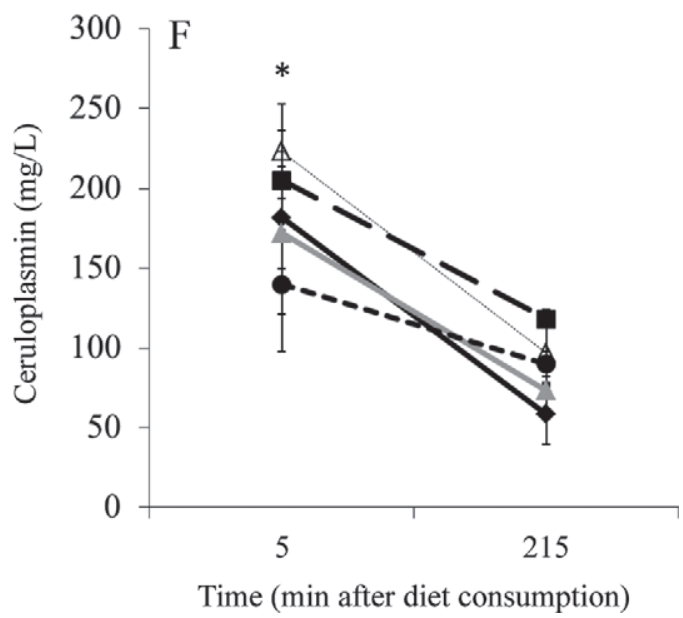

Figure 2. Plasma concentrations (means \pm SEM) of oxidative stress biomarkers 5 and 215 min after feed consumption in dairy heifers fed 5 different challenge diets $(\mathrm{n}=6$ heifers/group): control (no grain); $\mathrm{GR}=($ crushed triticale, $1.2 \%$ of $\mathrm{BW} \mathrm{DMI}) ; \mathrm{GR}+\mathrm{FR}=$ grain $(0.8 \%$ of $\mathrm{BW}$ $\mathrm{DMI})+$ fructose $(0.4 \%$ of BW DMI $) ; \mathrm{GR}+\mathrm{HIS}=\operatorname{grain}(1.2 \%$ of BW DMI $)+$ histidine $(6 \mathrm{~g} / \mathrm{head}) ; \mathrm{GR}+\mathrm{FR}+\mathrm{HIS}=$ grain $(0.8 \%$ of BW DMI $)$ + fructose $(0.4 \%$ of BW DMI) + histidine $(6 \mathrm{~g} /$ head). (A) Reactive oxygen metabolites (dROM), (B) biological antioxidant potential (BAP), (C) oxidative stress index (dROM:BAP), (D) advanced oxidation protein products (AOPP), (E) glutathione peroxidase (GSH-Px) activity, and (F) ceruloplasmin concentration. ${ }^{*} P<0.05$. 
ing that oxidative stress may not result from a single, albeit significant, carbohydrate challenge. Oxidative stress can result from more-acute grain challenges, as high levels of starch fed to dairy cows at 80 DIM increased oxidative stress (Gabai et al., 2004) and feeding early lactation cattle rations to achieve restricted or high milk production was associated with oxidative stress (Pedernera et al., 2010). Prolonged concentrate feeding in dairy cattle showed increased plasma glutathione peroxidase activity and lipid peroxidation and decreased $\alpha$-tocopherol and ferric reducing ability of plasma (Wullepit et al. 2009).

The lack of oxidative stress responses to treatment is consistent with the absence of treatment effects on ruminal endotoxin. Endotoxin translocation into the bloodstream may result in the production of oxidative molecules (Rietschel et al., 1994). The absence of a group effect on ruminal endotoxin suggests that blood endotoxin concentrations also were unlikely to have been increased.

The increase in OSI and dROM over time may have been a response to feeding after the withholding period or stress, independent of treatments. The increase in OSI and dROM in the control heifers supports this hypothesis. Withholding cattle from feed before offering the experimental diets may have increased glycogenolysis and gluconeogenesis and decreased oxidative phosphorylation, a contributor to $\mathrm{dROM}$ production. Therefore, the overall oxidative status (OSI) of the cattle could have been low before feeding and increased after. The increase in $\mathrm{dROM}$ and OSI may reflect stress from restraint and sampling over the 3.6-h period. Stress of any origin can deplete the body's antioxidant resources (Sconberg et al., 1993) and result in lipid oxidation in muscle (McClelland, 2004).

The observed range of dROM in this study (Figure $2 \mathrm{~A}$ ) was consistent with the ranges reported in dairy cattle (Bernabucci et al., 2005; Celi and Raadsma, 2010; Pedernera et al., 2010) but higher than those reported by Piccione et al. (2007) and Bernabucci et al. (2002). The BAP values reported in this study were slightly higher than those reported in dairy cattle (Celi and Raadsma, 2010; Pedernera et al., 2010). The observed increase in OSI over the experimental period can largely be attributed to the increase in dROM $215 \mathrm{~min}$ after feeding. The OSI concentrations were lower than those reported by Pedernera et al. (2010), but within the range reported for lactating dairy cattle by Celi and Raadsma (2010), despite the differing physiological states of heifers and lactating cows.

Advanced oxidation protein products are markers of protein oxidation generated by the reaction between plasma proteins and myeloperoxidase-derived chlorinated oxidants produced by activated neutrophils
(Witko-Sarsat et al., 1999). Concentrations of AOPP can be associated with embryonic losses and are considered an acute indicator of inflammation and oxidative stress in dairy cows (Celi et al., 2011). The lack of effects on AOPP may reflect the abrupt, as opposed to chronic, challenge in the study; however, we observed a trend toward a decrease in AOPP concentration in the control heifers over time.

Glutathione peroxidase is regarded as the most important hydrogen peroxide scavenging enzyme in mammalian cells (Halliwell, 1994) and is therefore considered a good indicator of oxidative stress (Gabai et al., 2004). The activity of GSH-Px was not affected by group, in contrast to alterations observed by Wullepit et al. (2009) in dairy cattle fed a grain carbohydrate challenge protocol. Celi et al. (2010) suggests that GSH-Px activity in the blood may not be very sensitive to nutritional changes. The activity of GSH-Px represents only one aspect of the antioxidant defense system; other enzymes such as catalase and superoxide dismutase may be better acute measures.

Ceruloplasmin (ferroxidase, EC 1.16.3.1) has both anti- and pro-oxidant roles (Healy and Tipton, 2007) and concentrations were within the proposed reference values for lactating Holsteins (Hussein et al., 2012). Ceruloplasmin concentrations decreased consistently across all groups contrary to the expected parallel increase with dROM, again suggesting that metabolic responses coped with this level of carbohydrate challenge.

\section{CONCLUSIONS}

Marked changes in ruminal metabolism during a single abrupt challenge with grain, fructose, and histidine, or their combinations, had no effect on ruminal endotoxin concentration or plasma oxidative stress biomarkers. Variable responses in ruminal endotoxin to carbohydrate challenge among studies suggest that further studies are needed to determine the thresholds required to induce endotoxin increases during abrupt carbohydrate challenges, or on other factors that influence endotoxin concentrations. The study shows that oxidative stress responses were not involved in responses to abrupt exposure to readily fermentable carbohydrates, both fructose and starch. This study contributes additional observations on the physiological ranges of oxidative stress biomarkers in ruminants.

\section{ACKNOWLEDGMENTS}

This work was supported by Dairy Australia (Southbank, VIC, Australia), SBScibus (Camden, NSW, Australia), DairyNSW (Mudgee, NSW, Australia), and The University of Sydney (Camden, NSW, Australia). 
The authors acknowledge the laboratory assistance of Carole Tooke (Lonza Australia Pty. Ltd., Mt. Waverley, VIC, Australia), Federica Caponnetto (University of Udine, Friuli-Venezia Giulia, Italy), and Aurora Maurizio (University of Udine, Friuli-Venezia Giulia, Italy).

\section{REFERENCES}

Ahrens, F. A. 1967. Histamine, lactic acid and hypertonicity as factors in the development of rumenitis in cattle. Am. J. Vet. Res. 28:1335-1342.

Alberti, A., L. Bolognini, D. Macciantelli, and M. Caratelli. 2000. The radical cation of $N, N$-diethyl-para-phenylendiamine: A possible indicator of oxidative stress in biological samples. Res. Chem. Intermed. 26:253-267.

Ametaj, B. N., Q. Zebeli, and S. Iqbal. 2010. Nutrition, microbiota, and endotoxin-related diseases in dairy cows. R. Bras. Zootec. 39:433-444.

Andersen, P. H., B. Bergelin, and K. A. Christensen. 1994. Effect of feeding regimen on concentration of free endotoxin in ruminal fluid of cattle. J. Anim. Sci. 72:487-491.

Andersen, P. H., and N. Jarlov. 1990. Investigation of the possible role of endotoxin, TXA2, PGI2, and PGE2 in experimentally induced acidosis in cattle. Acta Vet. Scand. 31:27-38.

Baek, L., N. Hoiby, J. B. Hertz, and F. Espersen. 1985. Interaction between Limulus amoebocyte lysate and soluble antigens from Pseudomonas aeruginosa and Staphylococcus aureus studied by quantitative immunoelectrophoresis. J. Clin. Microbiol. 22:229-237.

Benzie, I. F. F., and J. J. Strain. 1996. The ferric reducing ability of plasma (FRAP) as a measure of "antioxidant power": The FRAP assay. Anal. Biochem. 239:70-76.

Bernabucci, U., B. Ronchi, N. Lacetera, and A. Nardone. 2002. Markers of oxidative status in plasma and erythrocytes of transition dairy cows during hot season. J. Dairy Sci. 85:2173-2179.

Bernabucci, U., B. Ronchi, N. Lacetera, and A. Nardone. 2005. Influence of body condition score on relationships between metabolic status and oxidative stress in periparturient dairy cows. J. Dairy Sci. 88:2017-2026

Bramley, E., I. J. Lean, W. J. Fulkerson, M. A. Stevenson, A. R Rabiee, and N. D. Costa. 2008. The definition of acidosis in dairy herds predominantly fed on pasture and concentrates. J. Dairy Sci. 91:308-321.

Celi, P. 2011a. Oxidative stress in ruminants. Pages 191-231 in Studies on veterinary medicine. L. Mandelker and P. Vajdovich, ed. Humana Press, New York, NY.

Celi, P. 2011b. Biomarkers of oxidative stress in ruminant medicine. Immunopharmacol. Immunotoxicol. 33:233-240.

Celi, P., M. Merlo, L. Da Dalt, A. Stefani, O. Barbato, and G. Gabai. 2011. Relationship between late embryonic mortality and the increase in plasma advanced oxidised protein products (AOPP) in dairy cows. Reprod. Fertil. Dev. 23:527-533.

Celi, P., and H. W. Raadsma. 2010. Effects of yerba mate (Ilex paraguariensis) supplementation on the productive performance of dairy cows during mid-lactation. Anim. Prod. Sci. 50:339-344.

Celi, P., A. D. Trana, and S. Claps. 2010. Effects of plane of nutrition on oxidative stress in goats during the peripartum period. Vet. J. 184:95-99.

Cesarone, M. R., G. Belcaro, M. Carratelli, U. Cornelli, M. T. De Sanctis, L. Incandela, A. Barsotti, R. Terranova, and A. Nicolaides. 1999. A simple test to monitor oxidative stress. Int. Angiol. 18:127-130.

Emmanuel, D. G. V., S. M. Dunn, and B. N. Ametaj. 2008. Feeding high proportions of barley grain stimulates an inflammatory response in dairy cows. J. Dairy Sci. 91:606-614.

Enemark, J. M. D. 2008. The monitoring, prevention and treatment of sub-acute ruminal acidosis (SARA): A review. Vet. J. 176:32-43.
Firkins, J. L. 2011. Liquid feeds and sugars in diets for dairy cattle. Pages 62-80 in Proc. 2011 Florida Rum. Nutr. Symp., 22nd Annu. Mtg., Univ. Florida, Gainesville. University of Florida, Gainesville.

Gabai, G., S. Testoni, R. Piccinini, L. Marinelli, and G. Stradaioli 2004. Oxidative stress in primiparous cows in relation to dietary starch and the progress of lactation. Anim. Sci. 79:99-108.

Golder, H. M., P. Celi, A. R. Rabiee, C. Heuer, E. Bramley, S. W. Miller, R. King, and I. J. Lean. 2012. Effects of grain, fructose and histidine on ruminal $\mathrm{pH}$ and fermentation products during an induced subacute acidosis protocol. J. Dairy Sci. 95:1971-1982.

Gozho, G. N., D. O. Krause, and J. C. Plaizier. 2006. Rumen lipopolysaccharide and inflammation during grain adaptation and subacute ruminal acidosis in steers. J. Dairy Sci. 89:4404-4413.

Gozho, G. N., D. O. Krause, and J. C. Plaizier. 2007. Ruminal lipopolysaccharide concentration and inflammatory response during grain-induced subacute ruminal acidosis in dairy cows. J. Dairy Sci. 90:856-866.

Gozho, G. N., J. C. Plaizier, D. O. Krause, A. D. Kennedy, and K. M. Wittenberg. 2005. Subacute ruminal acidosis induces ruminal lipopolysaccharide endotoxin release and triggers an inflammatory response. J. Dairy Sci. 88:1399-1403.

Halliwell, B. 1994. Free radicals and antioxidants: A personal view. Nutr. Rev. 52:253-265.

Hayirli, A., R. R. Grummer, E. V. Nordheim, and P. M. Crump. 2003. Models for predicting dry matter intake of Holsteins during the prefresh transition period. J. Dairy Sci. 86:1771-1779.

Healy, J., and K. Tipton. 2007. Ceruloplasmin and what it might do. J. Neural Transm. 114:777-781.

Hussein, H., R. Staufenbiel, A. Müller, A. El-Sebaie, and M. Abd-ElSalam. 2012. Ceruloplasmin activity in Holstein dairy cows: Effects of lactation stages and anticoagulants. Comp. Clin. Pathol. 21:705-710.

Khafipour, E., D. O. Krause, and J. C. Plaizier. 2009a. A grain-based subacute ruminal acidosis challenge causes translocation of lipopolysaccharide and triggers inflammation. J. Dairy Sci. 92:10601070

Khafipour, E., D. O. Krause, and J. C. Plaizier. 2009b. Alfalfa pelletinduced subacute ruminal acidosis in dairy cows increases bacterial endotoxin in the rumen without causing inflammation. J. Dairy Sci. $92: 1712-1724$

Kleen, J. L., G. A. Hooijer, J. Rehage, and J. Noordhuizen. 2003. Subacute ruminal acidosis (SARA): A review. J. Vet. Med. A Physiol. Pathol. Clin. Med. 50:406-414.

Krause, K. M., and G. R. Oetzel. 2006. Understanding and preventing subacute ruminal acidosis in dairy herds: A review. Anim. Feed Sci. Technol. 126:215-236.

Li, S., E. Khafipour, D. O. Krause, A. Kroeker, J. C. RodriguezLecompte, G. N. Gozho, and J. C. Plaizier. 2012. Effects of subacute ruminal acidosis challenges on fermentation and endotoxins in the rumen and hindgut of dairy cows. J. Dairy Sci. 95:294-303.

McClelland, G. B. 2004. Fat to fire: The regulation of lipid oxidation with exercise and environmental stress. Comp. Biochem. Physiol. B Biochem. Mol. Biol. 139:443-460.

Miller, J. K., E. Brzezinska-Slebodzinska, and F. C. Madsen. 1993 Oxidative stress, antioxidants, and animal function. J. Dairy Sci. 76:2812-2823.

Motoi, Y., T. Oohashi, H. Hirose, M. Hiramatsu, S. Miyazaki, S. Nagasawa, and J. Takahashi. 1993. Turbidimetric-kinetic assay of endotoxin in rumen fluid or serum of cattle fed rations containing various levels of rolled barley. J. Vet. Med. Sci. 55:19-25.

Nagaraja, T. G., E. E. Bartley, L. R. Fina, and H. D. Anthony. 1978. Relationship of rumen gram-negative bacteria and free endotoxin to lactic acidosis in cattle. J. Anim. Sci. 47:1329-1337.

Nagaraja, T. G., and E. C. Titgemeyer. 2007. Ruminal acidosis in beef cattle: The current microbiological and nutritional outlook. J. Dairy Sci. 90(E. Suppl.):E17-E38.

Owens, F. N., D. S. Secrist, W. J. Hill, and D. R. Gill. 1998. Acidosis in cattle: A review. J. Anim. Sci. 76:275-286.

Pedernera, M., P. Celi, S. C. García, H. E. Salvin, I. Barchia, and W. J. Fulkerson. 2010. Effect of diet, energy balance and milk pro- 
duction on oxidative stress in early-lactating dairy cows grazing pasture. Vet. J. 186:352-357.

Penner, G. B., K. A. Beauchemin, and T. Mutsvangwa. 2007. Severity of ruminal acidosis in primiparous Holstein cows during the periparturient period. J. Dairy Sci. 90:365-375.

Piccione, G., M. Borruso, C. Giannetto, M. Morgante, and E. Giudice. 2007. Assessment of oxidative stress in dry and lactating cows. Acta Agric. Scand. A Anim. Sci. 57:101-104.

Plaizier, J. C., E. Khafipour, S. Li, G. N. Gozho, and D. O. Krause. 2012. Subacute ruminal acidosis (SARA), endotoxins and health consequences. Anim. Feed Sci. Technol. 172:9-21.

Plaizier, J. C., D. O. Krause, G. N. Gozho, and B. W. McBride. 2008. Subacute ruminal acidosis in dairy cows: The physiological causes, incidence and consequences. Vet. J. 176:21-31.

RAGFAR (Reference Advisory Group on Fermentative Acidosis of Ruminants). 2007. Ruminal acidosis-Aetiopathogenesis, prevention and treatment. A review for veterinarians and nutritional professionals. Blackwell Publishing Asia Pty. Ltd., Carlton, VIC, Australia.

Rietschel, E., T. Kirikae, F. Schade, U. Mamat, G. Schmidt, H. Loppnow, A. Ulmer, U. Zahringer, U. Seydel, and F. Di Padova. 1994. Bacterial endotoxin: Molecular relationships of structure to activity and function. FASEB J. 8:217-225.

Russell, J. B., and J. L. Rychlik. 2001. Factors that alter rumen microbial ecology. Science 292:1119-1122.

Sconberg, S., C. F. Nockels, B. W. Bennett, W. Bruyninckx, A. M. B. Blancquaert, and A. M. Craig. 1993. Effects of shipping, handling, adrenocorticotropic hormone, and epinephrine on $\alpha$-tocopherol content of bovine blood. Am. J. Vet. Res. 54:1287-1293.
Sunderman, F. W., Jr., and S. Nomoto. 1970. Measurement of human serum ceruloplasmin by its p-phenylenediamine oxidase activity. Clin. Chem. 16:903-910.

Witko-Sarsat, V., M. Friedlander, T. N. Khoa, C. Capeillère-Blandin, A. T. Nguyen, S. Canteloup, J.-M. Dayer, P. Jungers, T. Drüeke, and B. Descamps-Latscha. 1998. Advanced oxidation protein products as novel mediators of inflammation and monocyte activation in chronic renal failure. J. Immunol. 161:2524-2532.

Witko-Sarsat, V., T. Nguyen-Khoa, P. Jungers, T. B. Drüeke, and B. Descamps-Latscha. 1999. Advanced oxidation protein products as a novel molecular basis of oxidative stress in uraemia. Nephrol. Dial. Transplant. 14:76-78.

Wullepit, N., W. Fokkink, V. Fievez, J. R. Newbold, D. Fremaut, and S. De Smut. 2009. Influence of diet-induced sub-acute ruminal acidosis on the oxidative status of plasma in dairy cows. Pages 796-797 in Ruminant Physiology: Digestion, Metabolism, and Effects of Nutrition on Reproduction and Welfare. Proc. XIth Int. Symp. Rum. Physiol. Y. Chilliard, F. Glasser, Y. Faulconnier, F. Bocquier, I. Veisser, and M. Doreau, ed. Wageningen Academic Publishers, Wageningen, the Netherlands.

Zebeli, Q., S. M. Dunn, and B. N. Ametaj. 2011. Perturbations of plasma metabolites correlated with the rise of rumen endotoxin in dairy cows fed diets rich in easily degradable carbohydrates. J. Dairy Sci. 94:2374-2382.

Zebeli, Q., B. U. Metzler-Zebeli, and B. N. Ametaj. 2012. Meta-analysis reveals threshold level of rapidly fermentable dietary concentrate that triggers systemic inflammation in cattle. J. Dairy Sci 95:2662-2672. 